\title{
DESIGN AND DEVELOPMENT OF ELECTROMAGNETIC VIBRATION ABSORBER
}

\author{
Prathmesh Pradeep Patil \\ Department of Mechanical Engineering \\ Rajarambapu institute of Technology, \\ Islampur, India
}

\begin{abstract}
A novel semi active electromagnetic vibration absorber (SAEMVA) is developed. The main purpose of this study is to evaluate the dynamic characteristics of the damping controlled semi active tuned vibration absorber (TVA). A base-excited, single degree of freedom structure coupled with a TVA model is adopted as a baseline model for our analysis. In this stiffness can be controlled by external stimuli. This unique characteristic makes them feasible for use in devices designed for vibration control applications. In order to explore effectiveness of SAEMVA for vibration control, mathematical model for passive type vibration absorber and electromagnetic vibration absorber is prepared. This mathematical model is used to write MATLAB program. The results show that SAEMVA has ability to offer wide range of stiffness under influence of external stimuli and has, prospective in application where tuning vibration characteristics are desired. Also, it shows that SAEMVA performs superior to conventional passive vibration absorber in terms of capability to tune natural frequency of absorber and vibration absorption capacity.
\end{abstract}

Keywords - Tuned vibration absorber, Semi-active control, electromagnetic actuator

\section{INTRODUCTION}

Since its invention in the early 1900s, Tuned Vibration Absorbers (TVA) have been effective engineering devices that suppress vibrations of machines and structures excited by harmonic forces. A TVA is a vibratory subsystem, normally consisting of a mass, damper and a spring that is mounted on a primary system. The TVA counters the motion of the primary system by absorbing primary structures vibrations. However, the TVA is only effective over a narrow frequency range. As the excitation frequency varies, the vibration attenuation effect of the TVA decreases or vanishes because of the mistuning. This problem limits many applications of TVAs. One solution to this problem is to develop adaptive tuned vibration absorber. There are two types of adaptive tuned vibration absorber method: 1) active vibration control method 2) semiactive or semi-passive vibration control method. Passive control was the earliest developed vibration control technique. Passive control technique was flexible to implement no

\author{
Prof. Dr. S. S. Gawade \\ Department of Mechanical Engineering \\ Rajarambapu institute of Technology, \\ Islampur, India
}

sensors and power required and unconditional stable. Isolation is the most straightforward method in passive vibration control in which isolation of the vibrating structure carried out from its support to prevent the vibration transmitted to other equipment. Adding mass or stiffness to structure is equally helpful to control vibration. Besides this, we can also isolate the structure from the vibrating base, like inserting a spring under the seats in the vehicles. Vibration damping also achieved by modifying the dynamic properties of structure which applicable to control the vibration of central air condition and air compressor. Besides the previous techniques, several passive control methods are equally developed. The Tuned Mass Damper (TMD) is a popular passive control approach. In TMD method auxiliary device mounted on a host structure to absorb the structural mechanical energy when the structure vibrates at its resonant frequency. Its narrow bandwidth of vibration control is a primary disadvantage of this method. The passive control needed to include nonnegligible mass to the structure which could be unacceptable in the aerospace field. The active control vibration technique needs sensors to monitor the displacement or velocity of the structure. The sensed signals, later on, send to a controller (The microchip or computer embedded I/O board.) to procure a control signal by employing specific algorithms. The control signal amplified by a power amplifier or directly exerts on actuators to generate feedback force on the structure which typically has the other phase with the external excitation. The power consumption in active vibration control method is high enough and instability at high-frequency vibration control due to spill over. To achieve advantage both of the previous method, semi-active or semi-passive vibration control method used. Usually, this control technique is hysteretic or nonlinear in nature. By utilizing a moderate amount of energy, this system can convert the structural dynamic properties by changing the control state, which leads to vibration damping. The semi-active and semi-passive method distinguished on how they utilize minor external energy. In the semi passive method, external energy is used for power-up the control system and not for inducing the control force. In a semi-active method, external energy uses to induce control force. However, energy used in semi-active control is remarkably less as compared to the conventional active vibration control method. Several other control systems proposed and 


\section{International Journal of Engineering Applied Sciences and Technology, 2020 \\ Vol. 5, Issue 6, ISSN No. 2455-2143, Pages 318-323 \\ Published Online October 2020 in IJEAST (http://www.ijeast.com)}

investigated like active variable stiffness (AVS) in which the stiffness can switch between high and low values. A moderate amount of work carried out on electromagnetic vibration absorbers which absorb vibration by tuning the intensity of the electric field with the structural motion. Also compared with mechanical or hydraulic devices, electromagnetic devices possess some unique advantage such as cleanness, faster response time, no mechanical contact, easy integration with control system, compactness, etc.

\section{PROPOSED SYSTEM}

\section{1) Principal of Electromagnetic Vibration} ABSORBER

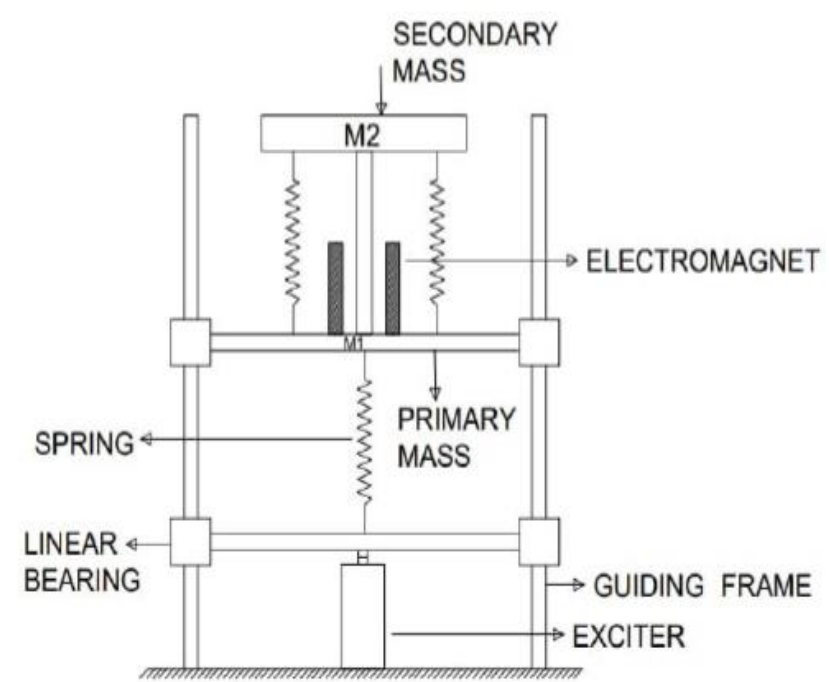

Fig.1.1- A primary system attached with an electromagnetic vibration absorber

Vibration absorber is elastically attached to the vibrating body to alleviate detrimental oscillations from its point of attachment. The above figure shows principle of electromagnetic vibration absorber; as shown schematically in Fig. the entire experimental system consists of three subsystems: EMVA, primary system, and computer control system. The EMVA contains the following parts: a permanent magnet (PM) that is embedded in the center of the secondary mass, and an electromagnet. The permanent magnet plays a dual role: acting as an absorber mass and forming a variable magnetic spring. By interacting with the electromagnet through varying the direct current (DC) of the electromagnetic coils. The working principal of absorber system is that, when the excitation frequency is equal to natural frequency of the absorber system (i.e. $\omega=\omega 2$ ), the main system amplitude becomes zero even though it is excited by harmonic force.

2) MATHEMATICAL MODELLING:
Mathematical modeling is the art of translating problems from an application area into tractable mathematical formulations whose theoretical and numerical analysis provides insight, answers, and guidance useful for the originating application. A model that is simplest and still retains the essential features of the gives system becomes an easy choice in all such cases.

a) Mathematical model for passive vibration absorber:

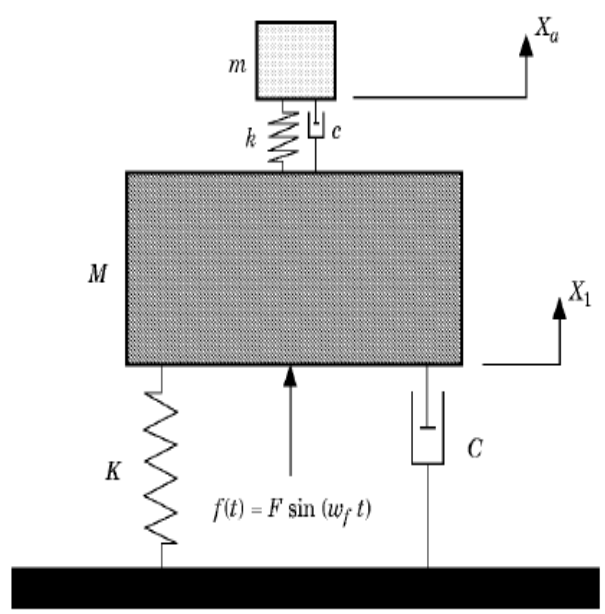

Fig.2.1- Passive type vibration absorber

Above figure shows passive type vibration absorber having excitations at primary system. In this model, the primary structure is coupled with a damped tuned vibration absorber and the mass of structure and absorber are defined by M1 and $\mathrm{M} 2$, with their corresponding displacements as X1 and X2 respectively. The absorbers spring (K2) and damper (C2) are mounted on the structure. The stiffness and damping of the structure are represented by $\mathrm{K} 1$ and $\mathrm{C} 1$, respectively.

Using Newton's second law of motion, as applied to the free body diagrams of the masses M1 and M2, the differential equation of motion is:

$\mathrm{m}_{1} \ddot{x}+\left(\mathrm{c}_{1}+\mathrm{c}_{2}\right) \dot{x}-\left(\mathrm{c}_{2} \cdot x_{2}\right)+\left(\mathrm{k}_{1}+\mathrm{k}_{2}\right) \cdot \mathrm{x}_{1}-\mathrm{k}_{2} \cdot \mathrm{x}_{2}=\mathrm{F}_{0}$

Where; $\mathrm{F}_{0}=\left(\mathrm{c}_{1} \cdot \mathrm{X}_{\text {in }}\right)+\left(\mathrm{k}_{1} \cdot \mathrm{X}_{\text {in }}\right)$

Similarly;

$\mathrm{m}_{2} \ddot{x_{2}}+\mathrm{k}_{2} \mathrm{x}_{2}-\mathrm{k}_{2} \mathrm{x}_{1}+\mathrm{c}_{2} x_{2}-\mathrm{c}_{2} \ddot{x}=0$

For steady state solution, assume solution as;

$\mathrm{X}_{1}=\mathrm{X} 1 . e^{s t}$

$\mathrm{X}_{2}=\mathrm{X}_{2} . e^{\text {st }}$;

$\mathrm{X}_{\text {in }}=\mathrm{Xin} . e^{s t}$

Where $s=j \omega$ and $\omega$ is driving frequency. Substituting for X1, $\mathrm{X} 2$, Xin and their second derivative in above equation, we have 


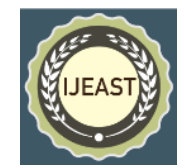

$\left[\begin{array}{cc}\mathrm{m} 1 s^{2}+(c 1+c 2) s+k 1+k 2 & -c 2 s-k 2 \\ -c 2 s-k 2 & m 2 s^{2}+c 2 s+k 2\end{array}\right] *\left(\begin{array}{c}x 1 \\ x_{2}\end{array}\right)=\left(\begin{array}{c}F 0 \\ 0\end{array}\right)$

Using Cremer's Rule, the amplitudes X1 and X2 can be solved for as

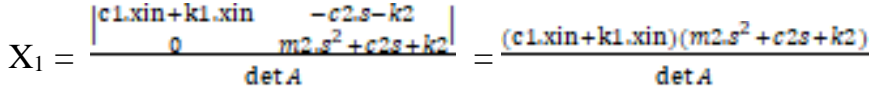

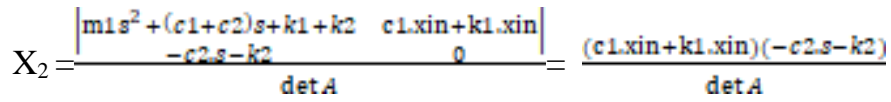

Therefore, the transmissibility equation becomes

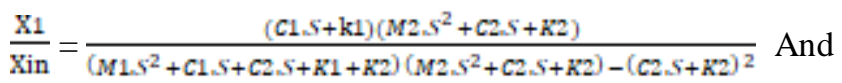

$$
\begin{aligned}
& \frac{\mathrm{X} 2}{\mathrm{Xin}}=\frac{(\mathrm{C1} S+\mathrm{k} 1)(\mathrm{C2} S+\mathrm{K} 2)}{\left(M 1 S^{2}+C 1 S+C 2 S+K 1+K 2\right)\left(M 2 S^{2}+C 2 S+K 2\right)-(C 2 S+K 2)^{2}}
\end{aligned}
$$

The above transmissibility equation will be used in the numerical simulation study of the vibration absorber in a MATLAB program.

\section{b) Mathematical model for electromagnetic vibration} absorber:

In an effort to enhance the performance of the traditional tuned vibration absorber, we have used electromagnetic actuating force $(\mathrm{u})$ between primary system and absorber system.

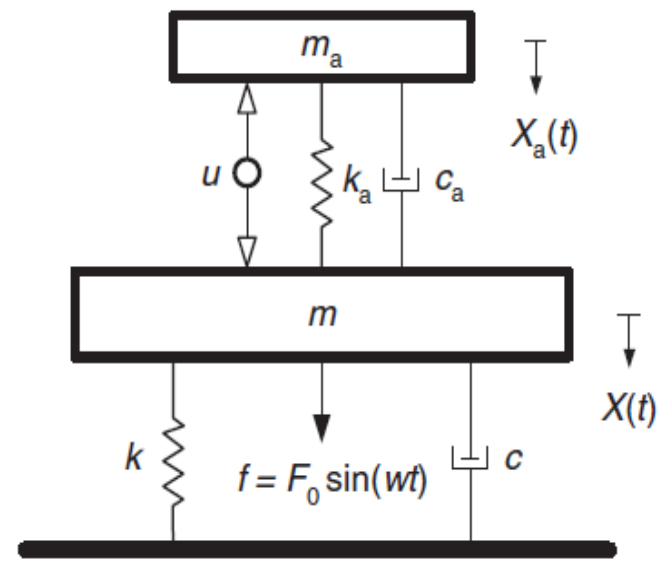

Fig.2.2- Semi active type vibration absorber

When the Electromagnetic Vibration Absorber is mounted on a one-floor structure, the entire system can be schematically represented by above figure. Where $M_{1}$ and $M_{2}$ are mass, $C_{1}$ and $C_{2}$ are damping value, $K_{1}$ and $K_{2}$ the stiffness of primary system and absorber system, respectively. $F_{0} \cdot \sin (\omega t)$ an external harmonic excitation; $\omega$ the excitation frequency; and $\mathrm{u}$ the actuating force. When we put $\mathrm{u}=0$, the absorber becomes the passive one.
The dynamic equations of the mechanical portion of the entire system can be written as;

$\mathrm{m} 1 \ddot{x}+(\mathrm{c} 1+\mathrm{c} 2) \dot{x}-\left(\mathrm{c} 2 \cdot x_{2}\right)+(\mathrm{k} 1+\mathrm{k} 2) \cdot \mathrm{x} 1-\mathrm{k} 2 \cdot \mathrm{x} 2=\mathrm{F} 0-$ fact

Similarly;

$\mathrm{m} 2 \ddot{x_{2}}+\mathrm{k} 2 \mathrm{x} 2-\mathrm{k} 2 \mathrm{x} 1+\mathrm{c} 2 x_{2}-\mathrm{c} 2 \dot{x}=$ fact

We can write above equation as follows:

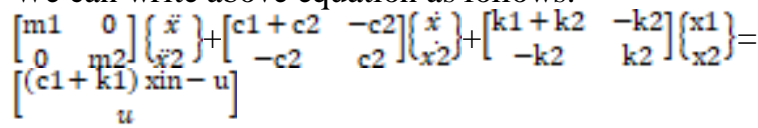

For steady state solution, assume solution as;

$\mathrm{x} 1=\mathrm{X}_{1} \cdot e^{s \mathrm{t}}$

$\mathrm{x} 2=\mathrm{X}_{2} \cdot e^{\mathrm{st}}$;

$\operatorname{xin}=X_{\text {in. }} \cdot e^{\text {st }}$

$\mathrm{u}=\mathrm{u}_{0} \cdot e^{\text {st }}$

Where $s=j \omega$ and $\omega$ is driving frequency.

Above equation is converted into Fourier transformation and is written as equation 3 , where $\mathrm{X}_{1}, \mathrm{X}_{2}$ and $\mathrm{F}_{\text {act }}$ are the Fourier Transformations of $\mathrm{X} 1, \mathrm{x} 2$ and $\mathrm{f}_{\text {act }}$ respectively.

By solving obtained equation, $\mathrm{X}_{1}$ and $\mathrm{X}_{2}$ can be derived as:

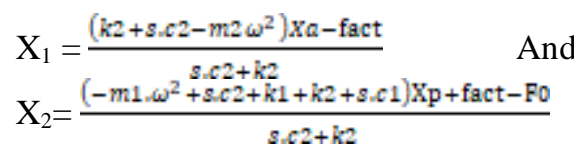

Combining above two equations we get,

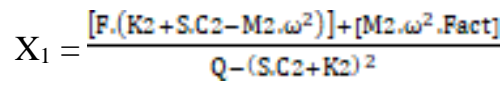

Put $\mathrm{X}_{1}=0$, we get

$\mathrm{F}_{\mathrm{act}}=\frac{-\mathrm{E} \cdot\left(\mathrm{K} 2+\mathrm{S} \cdot \mathrm{C} 2-\mathrm{M} 2 \omega^{2} \omega^{2}\right)}{\mathrm{M} 2 \cdot \omega^{2}}$

From the above transmissibility equation will be used in the numerical simulation study of the electromagnetic vibration absorber in a MATLAB program. And to draw graphs.

\section{c) Parameters selection for effective performance:}

For the experimental analysis of electromagnetic vibration absorber, excitor present at vibration laboratory RIT Islampur is SI-230 which is manufactured by Syscon Pvt. Ltd. The Specification of excitor is given below:

Peak sine force $=200 \mathrm{~N}$ And Max. Displacement $=12 \mathrm{~mm}$

Let's consider acceleration is $2 \mathrm{~m} / \mathrm{s}^{2}$

$\therefore \mathrm{a}=2 \mathrm{~m} / \mathrm{s}^{2} \quad$ so;

$\mathrm{M}=100 \mathrm{Kg} \ldots \ldots$. [Total mass of system sustainable]

Now consider mass ratio $(u)$ :

The mass ratio and stiffness range are selected to trace driving frequency range as wide as possible. Usually mass ratio is kept 0.05 to 0.25

Let's take $u=0.20$ 


\section{International Journal of Engineering Applied Sciences and Technology, 2020 \\ Vol. 5, Issue 6, ISSN No. 2455-2143, Pages 318-323 \\ Published Online October 2020 in IJEAST (http://www.ijeast.com)}

Now total mass of system is $10 \mathrm{Kg}$ where,

$\mathrm{M}_{1}=3 \mathrm{Kg} \quad$ and

$\mathrm{M}_{2}=0.6 \mathrm{Kg}$

The frequency $(\omega)$ we are going to take for experimental purpose is $50 \mathrm{rad} / \mathrm{sec}$

After solving for stiffness, we get;

$\mathrm{k}_{1}=7500 \mathrm{~N} / \mathrm{m}$ and $\mathrm{k}_{2}=1500 \mathrm{~N} / \mathrm{m}$

Now to find base excitations we use,

$\mathrm{X}_{\text {in }}=\frac{\mathbb{a}}{W^{r_{2}}}=0.0008 \mathrm{~m}$

After substituting above values in MATLAB program, we will get other required values such as $\omega 1, \omega 2$, both actuating forces $\left(f_{a c t}\right)$ etc.

\section{3) ADAPTIVITY OF DYNAMIC VIBRATION} ABSORBER:

Initially, it is assumed that the main system alone is subjected to excitation frequency equal to its natural frequency of main system which is $50 \mathrm{~Hz}$. At resonance, the steady state displacement of main system is $0.06 \mathrm{~m}$. To attenuate this amplitude at resonant frequency, absorber system is attached with main system with its natural frequency equal to driving frequency. After attaching absorber mass, frequency shift occurs at graph. New frequencies are $\omega 1=6.38$ and $\omega 2=$ 9.94. And for that frequency displacement are $0.01 \mathrm{~m}$ and $0.005 \mathrm{~m}$ respectively. Below graphs shows displacement vs frequency [Both in $\mathrm{rad} / \mathrm{sec}$ and $\mathrm{Hz}$ ] graphs and transmissibility vs frequency [Both in $\mathrm{rad} / \mathrm{sec}$ and $\mathrm{Hz}$ ] graph for passive type vibration absorber.

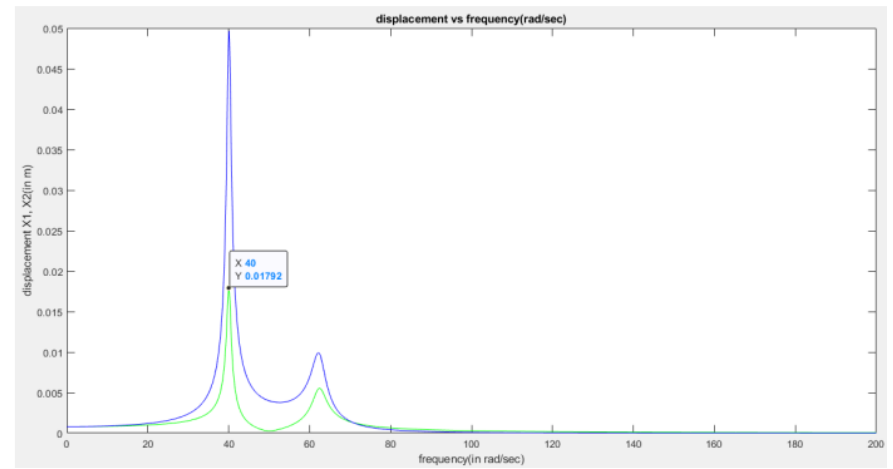

Fig.3.1 - Displacement Vs Frequency ( $\mathrm{rad} / \mathrm{sec})$

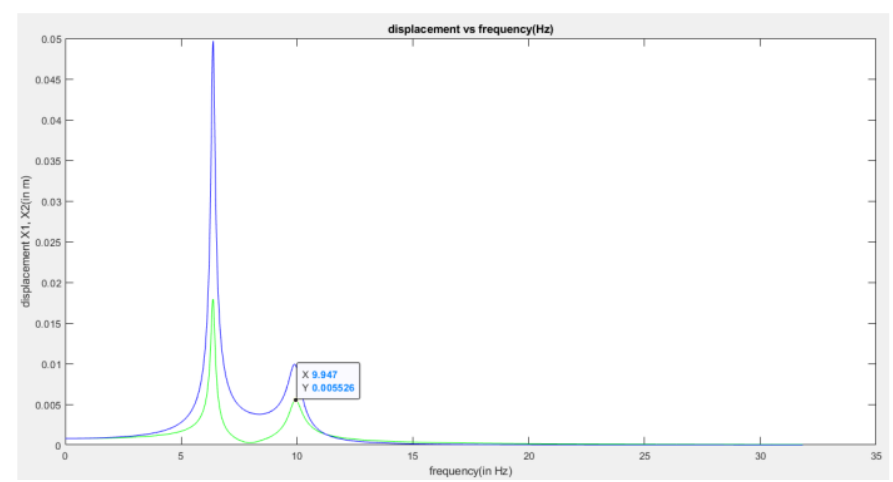

Fig.3.2 - Displacement Vs Frequency (Hz)

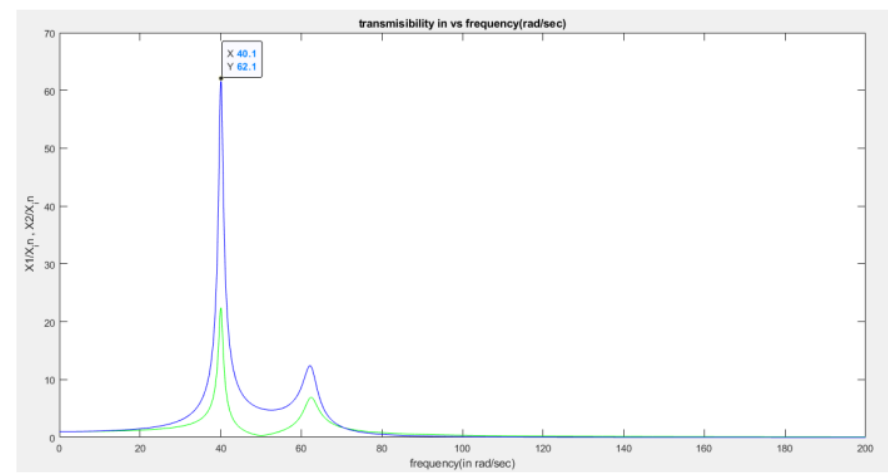

Fig.3.3 - Transmissibility Vs Frequency ( $\mathrm{rad} / \mathrm{sec})$

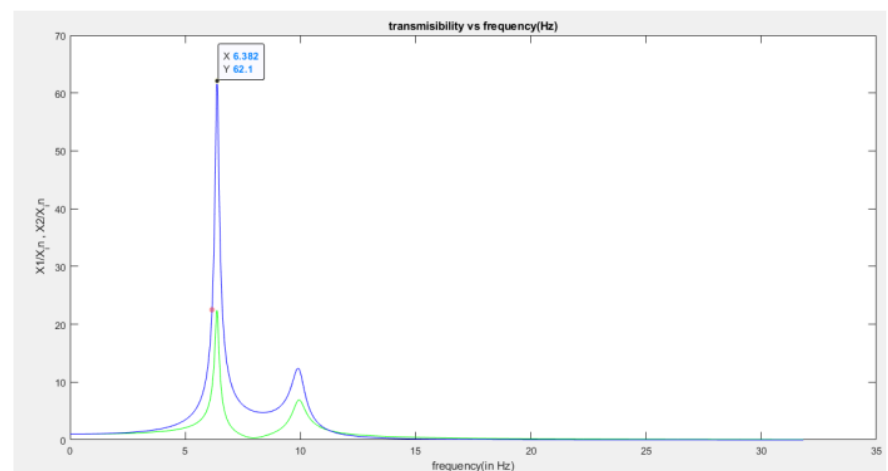

Fig.3.4 - Transmissibility Vs Frequency $(\mathrm{Hz})$

Now below graphs shows same scenario but before and after tuning i.e. electromagnetic actuating force. In this Red line shows response for before tuning and Green line shows response for after tuning i.e. with using electromagnetic actuating force. 


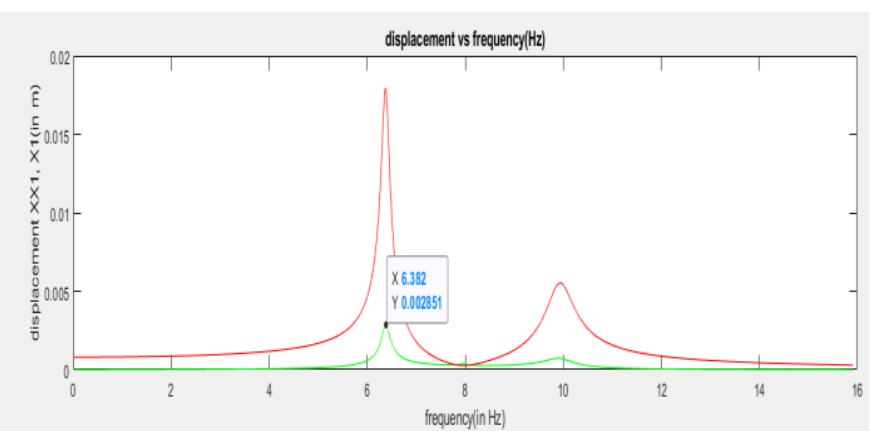

Fig.3.5 - Displacement Vs Frequency (Hz)

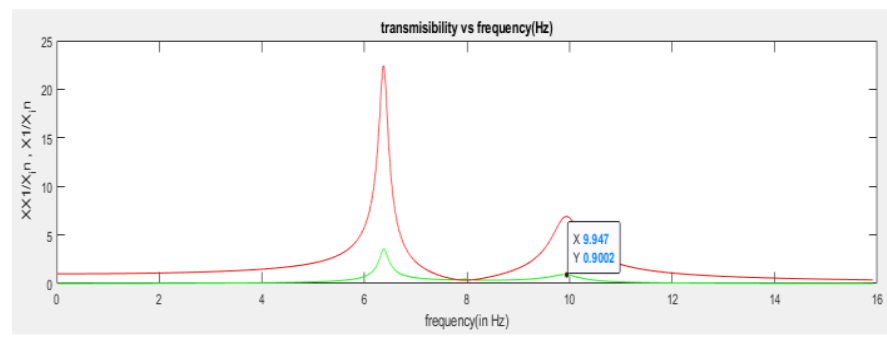

Fig.3.6 - Transmissibility Vs Frequency (Hz)

\section{RESULT AND DISCUSSION}

In this paper, dynamic performance of innovative electromagnetic vibration absorber has been studied in view of vibration control. The effect of variation of actuating force corresponded to varying frequency on displacement transmissibility and damping have been studied. Furthermore, vibration absorption ability of semi active electromagnetic vibration absorber, comparing passive type vibration absorber, has been studied.

i. Passive type vibration absorber [without actuating force]

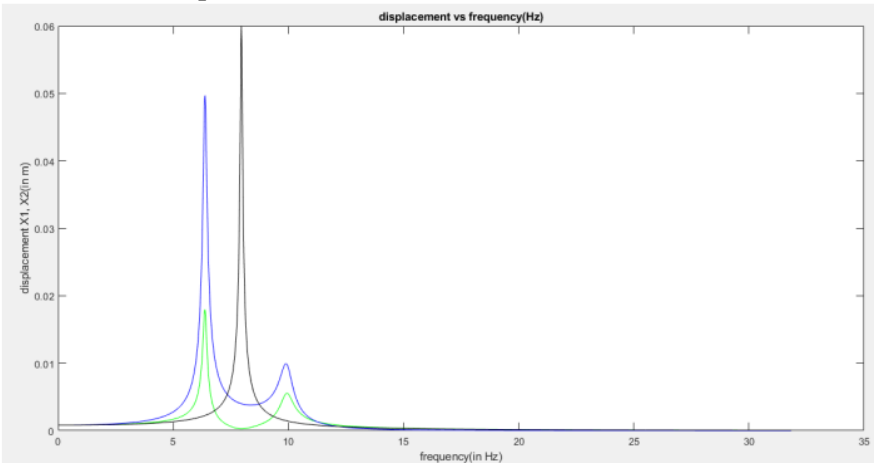

Fig.4.1 - Displacement Vs frequency $(\mathrm{Hz})$ for passive vibration absorber

In above figure, black colored peak shows natural frequency of main system. For which;

When $\omega=7.9 \mathrm{~Hz}$ then displacement $=0.06 \mathrm{~m}$

In the same figure, blue colored peak shows frequency response for subsystem (Passive absorber)
When $\omega 1=6.33 \mathrm{~Hz}$ then displacement $=0.04 \mathrm{~m}$

When $\omega 2=9.91 \mathrm{~Hz}$ then displacement $=0.009 \mathrm{~m}$

Similarly, green colored peak shows frequency response for main system

When $\omega 1=6.38 \mathrm{~Hz}$ then displacement $=0.01 \mathrm{~m}$

When $\omega 2=9.94 \mathrm{~Hz}$ then displacement $=0.005 \mathrm{~m}$

ii. Semi active type vibration absorber (With actuating force)

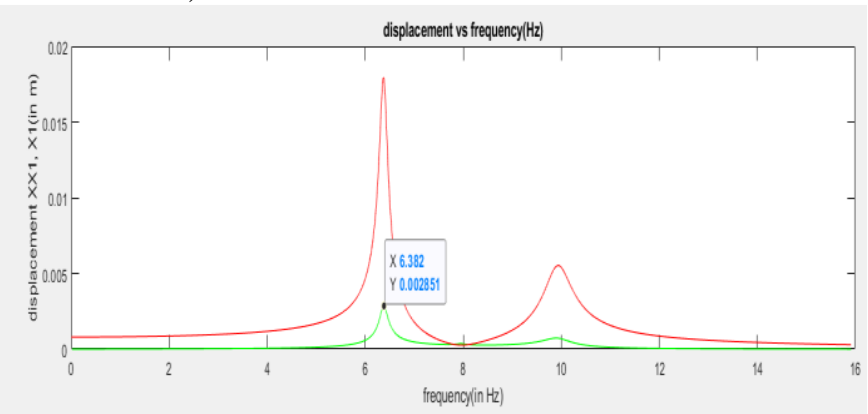

Fig.4.2 - Displacement Vs frequency (Hz) for semi active type vibration absorber

In above figure, red colored peak shows frequency response of main system (Before tuning)

When $\omega 1=6.38 \mathrm{~Hz}$ then displacement $=0.01 \mathrm{~m}$

When $\omega 2=9.94 \mathrm{~Hz}$ then displacement $=0.005 \mathrm{~m}$

Similarly, green colored peak shows frequency response of main system (After tuning)

When $\omega 1=6.38 \mathrm{~Hz}$ then displacement $=0.002 \mathrm{~m}$

When $\omega 2=9.91 \mathrm{~Hz}$ then displacement $=0.007 \mathrm{~m}$

Following table shows, change in displacement of main system along with type of absorber;

\begin{tabular}{|c|c|c|}
\hline $\begin{array}{c}\text { Type of } \\
\text { absorber }\end{array}$ & Frequency (Hz) & Displacement (m) \\
\hline Without absorber & 7.9 & 0.06 \\
\hline $\begin{array}{c}\text { Passive type } \\
\text { absorber }\end{array}$ & $\omega 1=6.38$ & 0.01 \\
\hline $2=9.94$ & 0.005 \\
\hline $\begin{array}{c}\text { Semi-active type } \\
\text { absorber }\end{array}$ & $\omega 1=6.36$ & 0.002 \\
\hline
\end{tabular}

Also, from work space, we can obtain values of actuating force $($ fact $)$

fact $=-3.3657$

fact $=2.14755$

\section{CONCLUSION}

Active systems have proven advantages in vibration control over passive systems, but the increase in cost and complexity when active systems are substituted for passive systems can be justified only in cases in which performance is critical. 


\section{International Journal of Engineering Applied Sciences and Technology, 2020 \\ Vol. 5, Issue 6, ISSN No. 2455-2143, Pages 318-323 \\ Published Online October 2020 in IJEAST (http://www.ijeast.com)}

However, when exciting frequency is shifting or system damping is not low, it becomes impossible to completely suppress the steady state vibration. That time semi active system is very useful over active system, because of its low cost, low militance and less complex structure.

Among various semi-active vibration absorber, electromagnetic vibration absorber is most promising because it has unique advantages such as cleanness, faster response time, no mechanical contact, compactness etc.

Mathematical model for passive type and semi active type vibration absorber is developed. The effect changing frequency is calculated. In this study, the results of mathematical model for both types of absorbers are obtained. It is observed that for change in frequency, actuating force changes which is in positive and negative form.

The MATLAB analysis results demonstrate that the proposed semi active vibration absorber has better performance than conventional passive absorber in terms of frequency shift property and vibration absorption capacity.

\section{REFERANCES}

1. Bae Jae-Sung, Hwang Jai-Hyuk, Roh Jin-Ho and Mi-Seon Yi (2015), "Development of an electromagnetic shock absorber". International Journal of Applied Electromagnetics and Mechanics 49 (2015) 157-167.

2. Alkhatib Rabih and Golnaraghi M. F., (2015), "Active Structural Vibration Control: A Review". The Shock and Vibration Digest 2003; 35; 367.

3. Marcus Vinícius, de Araujo Vitoratti, Nicoletti Rodrigo, (2014) "Electromagnetic harvester for lateral vibration in rotating machines", Journal of Vibration and Control 1-10.

4. Eissa M. and Sayed M., (2006) “a comparison between active and passive vibration control of non-linear simple pendulum", Mathematical and Computational Applications, Vol. 11, No. 2, pp. 151-162, 2006.

5. Liu J. and Liu K., (2006) "Application of an active electromagnetic vibration absorber in vibration suppression", Journal of Sound and Vibration 295 (2006) 708-724.

6. Collette Christophe, (2011), Review of Active Vibration Isolation Strategies, Bentham Science Publishers Ltd, vol-4, 1050-1058.

7. Hongpan Niu, (2008), Active Vibration Control of Beam Using Electro-Magnetic Constrained Layer Damping, Chinese Journal of Aeronautics, 115-124.

8. Miyamori Yasunori, (2004), Study on applicability of semiactive variable damping control on bridge structures under the large earthquake motion, 13th World Conference on Earthquake Engineering, 333-343.
9. Allen J. A., (2008) "Design of active suspension control based upon use of tubular linear motor and quarter-car model," Texas A\&M University.

10. Liu S. L. and Zheng S. Y., (2011) "Improved passive electromagnetic damper and its application," Journal of Vibration and Shock, vol. 30, pp. 94-97.

11. Kashem S. B. A., Chowdhury M. A., Choudhury T. A., Shabrin N., Ektesabi M., Nagarajah R., (2013), "Study and Comparison on Linear Electromagnetic Shock Absorbers among other Available Intelligent Vibration Dampers". International Journal of Science and Research (IJSR), 23197064.

12. Je-Hoon Kim, Jin-Ho Kim, Sang-Hyun Jeong, and BangWoo Han, (2012) "Design and Experiment of an Electromagnetic Vibration Exciter for the Rapping of an Electrostatic Precipitator". Journal of Magnetics 17(1), 61-67.

13. Krishnamoorthy Shanker Ganesh, Skiedraitė Inga, (2015) "Development of electromagnetic damper". ISSN 1392-1207. MECHANIKA. Volume 21(3): 226-233.

14. Franchek M. A., Ryan M. W. and Bernhard R. J., (1995) "Adaptive passive vibration control". Journal of Sound and Vibration, 565-585.

15. A. Gonzalez-Buelga, Clare L. R., Neild S. A., Burrow S. G. and Inman D. J., (2015) "An electromagnetic vibration absorber with harvesting and tuning capabilities". Structural Control and Health Monitoring. 